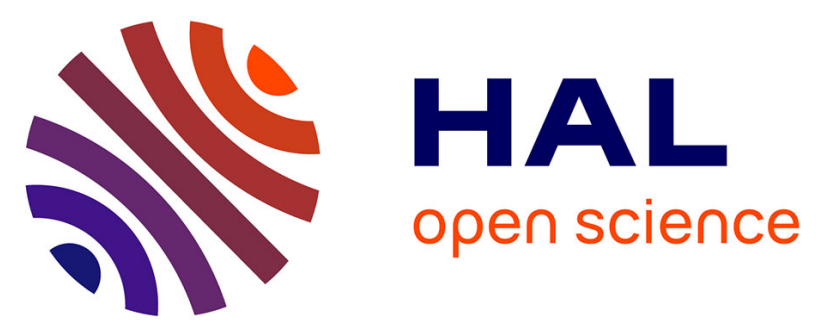

\title{
In vitro antimicrobial synergy testing of coagulase-negative staphylococci isolated from prosthetic joint infections using Etest and with a focus on rifampicin and linezolid
}

\author{
B. Hellmark, M. Unemo, Å. Nilsdotter-Augustinsson, B. Söderquist
}

\section{To cite this version:}

B. Hellmark, M. Unemo, Å. Nilsdotter-Augustinsson, B. Söderquist. In vitro antimicrobial synergy testing of coagulase-negative staphylococci isolated from prosthetic joint infections using Etest and with a focus on rifampicin and linezolid. European Journal of Clinical Microbiology and Infectious Diseases, 2010, 29 (5), pp.591-595. 10.1007/s10096-010-0902-6 . hal-00576102

\author{
HAL Id: hal-00576102 \\ https://hal.science/hal-00576102
}

Submitted on 12 Mar 2011

HAL is a multi-disciplinary open access archive for the deposit and dissemination of scientific research documents, whether they are published or not. The documents may come from teaching and research institutions in France or abroad, or from public or private research centers.
L'archive ouverte pluridisciplinaire HAL, est destinée au dépôt et à la diffusion de documents scientifiques de niveau recherche, publiés ou non, émanant des établissements d'enseignement et de recherche français ou étrangers, des laboratoires publics ou privés. 


\title{
In vitro antimicrobial synergy testing of coagulase-negative staphylococci isolated from prosthetic joint infections using Etest and with a focus on rifampicin and linezolid
}

\author{
B. Hellmark • M. Unemo • Å. Nilsdotter-Augustinsson • \\ B. Söderquist
}

Received: 30 September 2009 / Accepted: 20 February 2010/Published online: 12 March 2010

(C) Springer-Verlag 2010

\begin{abstract}
In recent years, coagulase-negative staphylococci (CoNS) have been increasingly recognised as causative agents of various infections, especially in immunocompromised patients and related to implanted foreign body materials. CoNS, and especially Staphylococcus epidermidis, transform into a stationary growth phase and produce biofilm when involved in a foreign body infection, making them difficult to eradicate with antimicrobials. Rifampicin has the ability to penetrate biofilm, but resistance may develop rapidly. To reduce the emergence of resistance, rifampicin should be combined with additional antimicrobials, of which several different ones have been proposed, including the relatively new class of antimicrobials, oxazolidinones, represented by linezolid. Thirty-seven CoNS isolates from patients with prosthetic joint infection were investigated by synergy testing using Etest. Nine antimicrobial combinations, based on either rifampicin or linezolid, were tested. For $16(43 \%)$ of the isolates, a synergistic $(n=5)$, additive $(n=14)$ and/or antagonistic $(n=11)$ effect were identified. In conclusion, Etest is an objective and easily performed in vitro method for antimicrobial synergy testing. However, each isolate requires testing for the specific combination considered for treatment.
\end{abstract}

B. Hellmark $(\bowtie) \cdot$ M. Unemo $\cdot$ B. Söderquist

Department of Laboratory Medicine, Clinical Microbiology,

Örebro University Hospital,

70185 Örebro, Sweden

e-mail: bengt.hellmark@orebroll.se

Å. Nilsdotter-Augustinsson

Division of Infectious Diseases,

Department of Clinical and Experimental Medicine,

Faculty of Health Sciences, University of Linköping,

Linköping, Sweden

B. Söderquist

Department of Infectious Diseases, Örebro University Hospital,

Örebro, Sweden

\section{Introduction}

Prosthetic joint infections (PJIs) are uncommon complications of prosthetic device surgery procedures, but represent harmful conditions with high morbidity and substantial costs. Coagulase-negative staphylococci (CoNS), and especially Staphylococcus epidermidis, is the most important pathogen involved in delayed or late onset PJIs [1]. There are no standards for the antimicrobial treatment of PJIs [2] and, during the recent decades, the treatment consisted predominately of cell wall antimicrobials such as isoxazolyl penicillin or glycopeptides [3]. However, without prosthetic joint exchange surgery, the long-term outcome has been disappointing, with a high rate of failures following finite treatment regimens [4-6]. S. epidermidis involved in a foreign body infection transforms into a stationary growth phase and produces biofilm. Therefore, cell wall antimicrobials may not be effective, since they do not efficiently penetrate the biofilm and have only a modest effect on bacteria in a non-growing phase [7]. Accordingly, additional antimicrobial agents and/or combinations of antimicrobials for the treatment of foreign body infections have been assessed. Predominantly antimicrobial combinations including rifampicin, which penetrates the biofilm and is effective also against stationary phase bacteria, have been investigated in experimental studies [8-10] as well as in clinical trials $[6,11,12]$. Resistance to rifampicin may rapidly emerge and, therefore, monotherapy should be avoided. To reduce the emergence of resistance to rifampicin, it is, accordingly, recommended to combine it with additional antimicrobials and several antimicrobials have been proposed, including fluoroquinolones [6], linezolid [13] and clindamycin [12]. In addition, linezolid may be a treatment option for multidrug-resistant (MDR) S. epidermidis, as monotherapy [13] or in combination with 
rifampicin [14]. However, concerns have been raised due to supposed in vitro antagonism between rifampicin and other antimicrobial agents [3]. This strengthens the need for synergy testing of antimicrobial combinations including rifampicin that are considered for treatment, which may also be needed for all antimicrobial combinations.

The aim of this study was to investigate antimicrobial combinations against $S$. epidermidis that may be of clinical interest for the long-term treatment of PJIs, focusing on rifampicin and linezolid. In vitro synergy testing was performed using Etest.

\section{Materials and methods}

Thirty-seven clinical CoNS isolates obtained during revision surgery for PJIs with extraction or exchange of the prosthetic devices were analysed. Multiple tissue biopsy

Table 1 Minimum inhibitory concentrations (MICs; $\mu \mathrm{g} / \mathrm{ml}$ ), using Etest, of six antimicrobials in coagulase-negative staphylococcal isolates $(n=37)$ from prosthetic joint infections

\begin{tabular}{|c|c|c|c|c|c|c|}
\hline & Rifampicin & Linezolid & Ciprofloxacin & Fusidic acid & Clindamycin & Trimethoprim-sulfamethoxazole \\
\hline S. epidermidis & $>32$ & 0.19 & 8 & 0.047 & 0.094 & $>640$ \\
\hline S. epidermidis & $>32$ & 0.047 & $>32$ & 6 & $>256$ & $>640$ \\
\hline S. epidermidis & 0.002 & 0.19 & 16 & 12 & $>256$ & $>640$ \\
\hline S. epidermidis & $>32$ & 0.19 & $>32$ & 6 & 0.023 & $>640$ \\
\hline S. epidermidis & $>32$ & 0.19 & $>32$ & 0.047 & $>256$ & $>640$ \\
\hline S. epidermidis & $<0.002$ & 0.125 & $>32$ & 6 & 0.047 & $>640$ \\
\hline S. epidermidis & $>32$ & 0.19 & $>32$ & 12 & $>256$ & $>640$ \\
\hline S. epidermidis & 0.25 & 0.125 & $>32$ & 12 & $>256$ & $>640$ \\
\hline S. epidermidis & 0.003 & 0.19 & $>32$ & 16 & $>256$ & $>640$ \\
\hline S. epidermidis & $>32$ & 0.19 & $>32$ & 0.047 & $>256$ & $>640$ \\
\hline S. epidermidis & 0.003 & 0.19 & $>32$ & 0.032 & $>256$ & 2.5 \\
\hline S. epidermidis & 0.003 & 0.25 & $>32$ & 12 & 0.064 & $>640$ \\
\hline S. epidermidis & $>32$ & 0.25 & $>32$ & 0.047 & $>256$ & $>640$ \\
\hline S. epidermidis & 6 & 0.125 & 3 & 0.032 & $>256$ & $>640$ \\
\hline S. epidermidis & 0.003 & 0.19 & $>32$ & 0.032 & $>256$ & $>640$ \\
\hline S. epidermidis & 0.003 & 0.25 & $>32$ & 0.023 & $>256$ & 320 \\
\hline S. epidermidis & $>32$ & 0.125 & $>32$ & 6 & $>256$ & $>640$ \\
\hline S. epidermidis & $>32$ & 0.25 & $>32$ & 0.047 & $>256$ & $>640$ \\
\hline S. epidermidis & 0.003 & 0.25 & $>32$ & 0.032 & $>256$ & $>640$ \\
\hline S. epidermidis & 0.002 & 0.25 & $>32$ & 6 & $>256$ & $>640$ \\
\hline S. epidermidis & $>32$ & 0.19 & 0.19 & 0.023 & $>256$ & $>640$ \\
\hline S. epidermidis & $>32$ & 0.19 & 6 & 0.023 & $>256$ & $>640$ \\
\hline S. epidermidis & $>32$ & 0.19 & 0.047 & 0.047 & $>256$ & $>640$ \\
\hline S. epidermidis & 0.002 & 0.38 & 16 & 6 & 0.094 & 480 \\
\hline S. epidermidis & 0.003 & 0.25 & 0.19 & 0.047 & 0.125 & 5 \\
\hline S. epidermidis & 0.003 & 0.38 & 16 & 0.064 & 0.064 & $>640$ \\
\hline S. epidermidis & 0.003 & 0.25 & $>32$ & 4 & $>256$ & $>640$ \\
\hline S. epidermidis & 0.003 & 0.25 & 0.19 & 0.047 & 0.094 & 0.64 \\
\hline S. epidermidis & 0.003 & 0.25 & $>32$ & 0.016 & 0.064 & 480 \\
\hline S. epidermidis & 0.003 & 0.19 & $>32$ & 8 & 0.094 & $>640$ \\
\hline S. epidermidis & 0.003 & 0.25 & 0.25 & 0.125 & $>256$ & 0.94 \\
\hline S. epidermidis & 0.004 & 0.19 & 0.19 & 0.032 & $>256$ & 3.8 \\
\hline S. epidermidis & 0.003 & 0.38 & 0.38 & 0.032 & 0.125 & 0.94 \\
\hline S. capitis & 0.012 & 0.38 & 0.125 & 0.064 & 0.19 & 1.88 \\
\hline S. haemolyticus & 0.006 & 0.38 & $>32$ & 12 & $>256$ & 240 \\
\hline S. simulans & 0.006 & 0.5 & 4 & 0.047 & 0.19 & 15 \\
\hline S. lugdunensis & $<0.002$ & 0.094 & 0.25 & 0.047 & 0.064 & 1.88 \\
\hline
\end{tabular}


samples, usually five or more, were taken perioperatively. The isolates were collected from patients with infected hip $(n=27)$, knee $(n=9)$ and elbow joint $(n=1)$ prostheses. The isolates comprised $S$. epidermidis $(n=33)$, S. capitis $(n=1)$, $S$. haemolyticus $(n=1), S$. simulans $(n=1)$ and $S$. lugdunensis $(n=1)$. The minimum inhibitory concentrations (MICs, $\mu \mathrm{g} / \mathrm{mL}$ ) of all antimicrobials were determined using the Etest method (AB Biodisk, Solna, Sweden). Rifampicin and linezolid were tested in combination with each other and with clindamycin, fusidic acid, ciprofloxacin and trimethoprim-sulfamethoxazole (SXT), respectively. First, the MIC for each antimicrobial was determined according to the guidelines from the Swedish Reference Group for Antibiotics (SRGA; http://www.srga.org). For the combination (synergy) testing, two methods, fixed ratio and MIC/ MIC ratio, were performed [15-17]. Briefly, in the fixed ratio method, an Etest strip of the first antimicrobial was placed on an agar plate, its exact location marked on the back of the plate, and incubated for $1 \mathrm{~h}$ at room temperature. Then, the Etest strip was removed and an Etest strip of the second antimicrobial was placed at the same location on the agar plate as the first strip. In the MIC/ MIC ratio method, an Etest strip of the first antimicrobial was placed on an agar plate, with the location and the MIC value from the single testing marked on the back of the plate, and incubated for $1 \mathrm{~h}$ at room temperature. Then, the Etest strip was removed and an Etest strip of the second antimicrobial was superimposed so that the respective MIC values from the single testing were aligned. All tests were performed on IsoSensitest agar (Oxoid, Hampshire, England) and at $36^{\circ} \mathrm{C}$ aerobic atmosphere for $18-24 \mathrm{~h}$.
In order to determine whether each specific combination of antimicrobials resulted in a synergistic, additive, indifferent or antagonistic effect, the fractional inhibitory concentration (FIC) index was calculated as previously described [15]. The following cut-off values and interpretative criteria in regards of the achieved effect were used; FIC index $\leq 0.5$ indicated a synergistic effect, FIC index $>0.5$ and $\leq 1.0$ an additive effect, FIC index $>1.0$ and $\leq 4.0$ indifferent effect, and FIC index $>4.0$ an antagonistic effect [15]. Random isolates were repeatedly analysed in order to assess the reproducibility.

\section{Results and discussion}

The MIC values for all isolates and all antimicrobial agents in single use are shown in Table 1.

Altogether, 888 MIC determinations were performed using the fixed ratio method and the MIC/MIC ratio method. The results of the MIC/MIC ratio method were more reproducible and easier to interpret, especially when evaluating two antimicrobials with substantial differences in their MIC values. Accordingly, the results of the antimicrobial synergy testing, using Etest and the $\mathrm{MIC} /$ MIC ratio method, of all isolates and antimicrobial combinations are summarised in Table 2.

Overall, $16(43 \%)$ of the isolates displayed a synergistic $(n=5)$, additive $(n=14)$ or antagonistic $(n=11)$ effect when combining two antimicrobials (Table 2).

The combination of rifampicin and ciprofloxacin displayed no synergistic effect in vitro. Instead, there were two $(5 \%)$

Table 2 Antimicrobial synergy testing, using Etest, of coagulase-negative staphylococcal isolates $(n=37)$ from prosthetic joint infections

\begin{tabular}{|c|c|c|c|c|}
\hline \multirow[t]{2}{*}{ Antimicrobial combination ${ }^{\mathrm{a}}$} & \multicolumn{4}{|c|}{ Number $(\%)$ of isolates } \\
\hline & Synergism & Addition & Indifference & Antagonism \\
\hline $\mathrm{RI}+\mathrm{LZ}$ & 0 & 0 & $36(97 \%)$ & $1(3 \%)$ \\
\hline $\mathrm{RI}+\mathrm{CI}$ & 0 & 0 & $35(95 \%)^{b}$ & $2(5 \%)$ \\
\hline $\mathrm{RI}+\mathrm{FU}$ & $2(5 \%)$ & 0 & $35(95 \%)$ & 0 \\
\hline $\mathrm{RI}+\mathrm{CM}$ & 0 & $4(11 \%)^{\mathrm{c}}$ & $33(89 \%)$ & 0 \\
\hline $\mathrm{RI}+\mathrm{SXT}$ & 0 & $1(3 \%)$ & $36(97 \%)^{\mathrm{d}}$ & 0 \\
\hline $\mathrm{LZ}+\mathrm{CI}$ & 0 & $1(3 \%)$ & $35(95 \%)$ & $1(3 \%)$ \\
\hline $\mathrm{LZ}+\mathrm{FU}$ & $1(3 \%)$ & $6(16 \%)$ & $30(81 \%)^{\mathrm{e}}$ & 0 \\
\hline $\mathrm{LZ}+\mathrm{CM}$ & $2(5 \%)$ & $2(5 \%)$ & $30(81 \%)$ & $3(8 \%)$ \\
\hline $\mathrm{LZ}+\mathrm{SXT}$ & 0 & 0 & $33(89 \%)$ & $4(11 \%)$ \\
\hline
\end{tabular}

${ }^{a}$ RI, rifampicin; LZ, linezolid; CI, ciprofloxacin; FU, fusidic acid; CM, clindamycin; SXT, trimethoprim-sulfamethoxazole

${ }^{\mathrm{b}}$ Including one strain not possible to distinguish between indifferent and additive effect

${ }^{\mathrm{c}}$ Including two strains not possible to distinguish between additive and synergistic effect

${ }^{\mathrm{d}}$ Including two strains not possible to distinguish between indifferent and additive effect

${ }^{\mathrm{e}}$ Including one strain not possible to distinguish between indifferent and additive effect and one strain not possible to completely distinguish between additive and synergistic effect 
isolates showing an antagonistic effect with an increase of the ciprofloxacin MIC from $6 \mu \mathrm{g} / \mathrm{ml}$ and $8 \mu \mathrm{g} / \mathrm{ml}$, respectively, to $>32 \mu \mathrm{g} / \mathrm{ml}$. For rifampicin and fusidic acid, two isolates $(5 \%)$ displayed a synergistic effect, with a decrease of the rifampicin MIC from $>32 \mu \mathrm{g} / \mathrm{ml}$ to $8 \mu \mathrm{g} / \mathrm{ml}$ and $0.125 \mu \mathrm{g} / \mathrm{ml}$, respectively, as well as of fusidic acid from $6 \mu \mathrm{g} / \mathrm{ml}$ and $12 \mu \mathrm{g} / \mathrm{ml}$ to $1.5 \mu \mathrm{g} / \mathrm{ml}$ and $0.064 \mu \mathrm{g} / \mathrm{ml}$, respectively. For rifampicin and clindamycin, four isolates $(11 \%)$ displayed an additive effect, with a decrease of the clindamycin MIC from $>256 \mu \mathrm{g} / \mathrm{ml}(n=3)$ to $0.94 \mu \mathrm{g} / \mathrm{ml}$ $(n=2)$ and $128 \mu \mathrm{g} / \mathrm{ml}$, respectively, and one additional isolate displayed a decrease from $0.19 \mu \mathrm{g} / \mathrm{ml}$ to $0.064 \mu \mathrm{g} / \mathrm{ml}$.

Linezolid comprises no known cross-resistance to other antimicrobials and is highly effective against Gram-positive bacteria. However, the treatment is expensive and long-term use may cause adverse effects $[13,18]$. For the combination rifampicin and linezolid, no synergistic or additive effects were found in the present in vitro test, but in a previous study by Jacqueline et al. [19], using the time-kill curve method, an additive effect could be seen. This has also been indicated in clinical studies [13, 14]. Accordingly, this combination treatment may have a synergistic effect in vivo. Regarding linezolid and fusidic acid, almost $20 \%$ of the isolates displayed a positive effect (synergistic or additive). For linezolid and clindamycin, all three effects were found, i.e. two isolates $(5 \%)$ displayed synergistic effect, two $(5 \%)$ additive effects and three (8\%) antagonistic effects. Clindamycin might be of clinical interest as the empirical treatment of PJIs, since it has a good effect on aerobic as well as anaerobic bacteria. Linezolid in combination with trimethoprim-sulfamethoxazole displayed the highest percentage of antagonistic effect (four isolates; 11\%), with an increase of linezolid MIC by 2 to 3 whole MIC steps, while rifampicin and trimethoprim-sulfamethoxazole displayed no antagonistic effect and one isolate (3\%) displayed an additive effect.

The reproducibility of the antimicrobial synergy testing using Etest was high (data not shown). Ideally, the Etest method for synergy testing of staphylococci should be further validated to a "gold standard," such as checkerboard titration or any in vitro kinetic model for synergy testing. However, there have been studies comparing Etest, the time-kill curve method and/or checkerboard methods for organisms such as Acinetobacter baumannii [20], Candida species [21] and Burkholderia cepacia [15]. All of these studies concluded that Etest is simple to use, time-efficient, reproducible and has good agreement to other methods for synergy testing. However, additional investigations are needed. A limitation of this study was that only bacteria in the growth phase, and not in the stationary phase protected by biofilm, were examined. Accordingly, the results may not completely reflect the situation in vivo during a PJI, but examine interesting antimicrobial combinations and their interactions in vitro.

In conclusion, Etest is an objective and easily performed in vitro method for the antimicrobial synergy testing of CoNS. However, the effects of different combinations of antimicrobials were strain-dependent and, accordingly, each isolate needs to be tested for the specific antimicrobial combination considered for treatment.

\section{References}

1. Zimmerli W, Trampuz A, Ochsner PE (2004) Prosthetic-joint infections. N Engl J Med 351(16):1645-1654

2. Esposito S, Leone S (2008) Prosthetic joint infections: microbiology, diagnosis, management and prevention. Int $\mathrm{J}$ Antimicrob Agents 32 (4):287-293

3. Zavasky DM, Sande MA (1998) Reconsideration of rifampin: a unique drug for a unique infection. JAMA 279(19):1575-1577

4. Collins DN, McKenzie JM (1991) Infections at the site of a hip implant. Successful and unsuccessful management. Clin Orthop Relat Res 269:9-15

5. Marculescu CE, Berbari EF, Hanssen AD, Steckelberg JM, Harmsen SW, Mandrekar JN, Osmon DR (2006) Outcome of prosthetic joint infections treated with debridement and retention of components. Clin Infect Dis 42(4):471-478

6. Zimmerli W, Widmer AF, Blatter M, Frei R, Ochsner PE (1998) Role of rifampin for treatment of orthopedic implant-related staphylococcal infections: a randomized controlled trial. ForeignBody Infection (FBI) Study Group. JAMA 279(19):1537-1541

7. Trampuz A, Osmon DR, Hanssen AD, Steckelberg JM, Patel R (2003) Molecular and antibiofilm approaches to prosthetic joint infection. Clin Orthop Relat Res 414:69-88

8. Schwank S, Rajacic Z, Zimmerli W, Blaser J (1998) Impact of bacterial biofilm formation on in vitro and in vivo activities of antibiotics. Antimicrob Agents Chemother 42(4):895-898

9. Svensson E, Hanberger H, Nilsson LE (1997) Pharmacodynamic effects of antibiotics and antibiotic combinations on growing and nongrowing Staphylococcus epidermidis cells. Antimicrob Agents Chemother 41(1): 107-111

10. Widmer AF, Frei R, Rajacic Z, Zimmerli W (1990) Correlation between in vivo and in vitro efficacy of antimicrobial agents against foreign body infections. J Infect Dis 162(1):96-102

11. Berdal JE, Skråmm I, Mowinckel P, Gulbrandsen P, Bjørnholt JV (2005) Use of rifampicin and ciprofloxacin combination therapy after surgical debridement in the treatment of early manifestation prosthetic joint infections. Clin Microbiol Infect 11(10):843-845

12. Soriano A, García S, Bori G, Almela M, Gallart X, Macule F, Sierra J, Martínez JA, Suso S, Mensa J (2006) Treatment of acute postsurgical infection of joint arthroplasty. Clin Microbiol Infect 12 (9):930-933

13. Soriano A, Gómez J, Gómez L, Azanza JR, Pérez R, Romero F, Pons M, Bella F, Velasco M, Mensa J (2007) Efficacy and tolerability of prolonged linezolid therapy in the treatment of orthopedic implant infections. Eur J Clin Microbiol Infect Dis 26(5):353-356

14. Senneville E, Legout L, Valette M, Yazdanpanah Y, Beltrand E, Caillaux M, Migaud H, Mouton Y (2006) Effectiveness and tolerability of prolonged linezolid treatment for chronic osteomyelitis: a retrospective study. Clin Ther 28(8):1155-1163

15. Manno G, Ugolotti E, Belli ML, Fenu ML, Romano L, Cruciani M (2003) Use of the E test to assess synergy of antibiotic combinations against isolates of Burkholderia cepacia-complex from patients with cystic fibrosis. Eur J Clin Microbiol Infect Dis 22(1):28-34 
16. Pankey GA, Ashcraft DS (2005) In vitro synergy of ciprofloxacin and gatifloxacin against ciprofloxacin-resistant Pseudomonas aeruginosa. Antimicrob Agents Chemother 49 (7):2959-2964

17. Tsuji BT, Rybak MJ (2006) Etest synergy testing of clinical isolates of Staphylococcus aureus demonstrating heterogeneous resistance to vancomycin. Diagn Microbiol Infect Dis 54(1):73-77

18. Rao N, Ziran BH, Wagener MM, Santa ER, Yu VL (2004) Similar hematologic effects of long-term linezolid and vancomycin therapy in a prospective observational study of patients with orthopedic infections. Clin Infect Dis 38(8):1058-1064

19. Jacqueline C, Caillon J, Le Mabecque V, Miegeville AF, Donnio PY, Bugnon D, Potel G (2003) In vitro activity of linezolid alone and in combination with gentamicin, vancomycin or rifampicin against methicillin-resistant Staphylococcus aureus by time-kill curve methods. J Antimicrob Chemother 51 (4):857-864

20. Bonapace CR, White RL, Friedrich LV, Bosso JA (2000) Evaluation of antibiotic synergy against Acinetobacter baumannii: a comparison with Etest, time-kill, and checkerboard methods. Diagn Microbiol Infect Dis 38(1):43-50

21. Lewis RE, Diekema DJ, Messer SA, Pfaller MA, Klepser ME (2002) Comparison of Etest, chequerboard dilution and timekill studies for the detection of synergy or antagonism between antifungal agents tested against Candida species. J Antimicrob Chemother 49(2):345-351 